\title{
MARTÍneZ-VÁzqUEZ, Jorge y LAGo PEÑAS, Santiago (dirs.): Desafíos pendientes de la descentralización en España: Suficiencia y autonomía tributaria
}

\author{
MARTíneZ-VÁzQuez, Jorge \& LAGo Peñas, Santiago (dirs.): \\ Desafíos pendientes de la descentralización en España: \\ Suficiencia y autonomía tributaria
}

\author{
Sonia Elizabeth Ramos-Medina \\ Universidad de Salamanca (España) \\ ORCID: https://orcid.org/0000-0003-0760-327X \\ elizabeth.ramos@usal.es
}

\section{NOTA BIOGRÁFICA}

Doctora en Estudios Fiscales por la Universidad Autónoma de Sinaloa (UAS), México. Becaria posdoctoral en España por el Consejo Nacional de Ciencia y Tecnología (CONACYT). Líneas de investigación son: Federalismo fiscal, Hacienda pública.

\section{RESUMEN}

Recensión: MARtínez-VÁzquez, Jorge y LAgo PeÑas, Santiago (dirs.): Desafíos pendientes de la descentralización en España: Suficiencia y autonomía tributaria. Madrid, España: Instituto de Estudios Fiscales (IEF), 2020, 322 págs.

\section{PALABRAS CLAVE}

Descentralización; Autonomía Tributaria; Suficiencia Tributaria.

\section{ABSTRACT}

Review: Martínez-Vázquez, Jorge \& Lago Peñas, Santiago (dirs.): Desafíos pendientes de la descentralización en España: Suficiencia y autonomía tributaria. Madrid, España: Instituto de Estudios Fiscales (IEF), 2020, 322 pp.

\section{KEYWORDS}

Decentralization; Tax Autonomy; Tax Sufficiency.

La entrada en vigor del Sistema de Financiación Autonómica (1978) constituye uno de los temas más controversiales en el proceso de descentralización. El modelo y la Ley Orgánica de Financiación de las Comunidades Autónomas (LOFCA) han experimentado sucesivas reformas sin resolver los problemas de origen sobre equidad y eficiencia (Calvo, 2015; Manzano, 2012). Esto ha supuesto una tendencia: hacerlo más complicado y menos comprensible para el ciudadano.

Esta lectura es fundamental por sus reflexiones desde varios enfoques disciplinarios se recomienda para funcionarios públicos e investigadores; pero, sobre todo resulta relevante para mitigar la percepción 
borrosa de la ciudadanía hacia las responsabilidades políticas de los gobernantes en materia de financiación autonómica (Lago Montero, 2014).

Es una obra colectiva cuya propuesta fundamental se basa en el análisis de dos principios de máxima relevancia para el adecuado funcionamiento del Sistema de Financiación Autonómica (SFA): suficiencia y autonomía.

El trabajo cuenta con aportaciones de dieciocho autores procedentes en su mayoría del ámbito académico, que analizan, discuten y formulan propuestas de mejora al SFA, que pueden servir como una guía en futuras negociaciones para la reforma del Sistema. Los once capítulos discurren con el siguiente hilo conductor: la suficiencia financiera del sistema de financiación autonómica; la autonomía tributaria de las Comunidades Autónomas (CC.AA); y, el futuro de la imposición patrimonial en España, que a su vez corresponden a los tres bloques en los que se encuentra dividido el texto. Por lo que se sugiere que el orden de lectura sea riguroso.

El primero (Cap. I-III) comienza con reflexiones sobre los supuestos comúnmente usados por las CC.AA: insuficiencia de recursos y desequilibrio vertical del SFA. Con un repaso a la historia reciente de las cuentas públicas se demuestra que no hay evidencia clara de un desequilibrio en la distribución de los recursos entre la Administración Central y las CC.AA y aunque esto sea demostrado, no significa que el escenario sea óptimo o que no requiera mecanismos de ajuste. Ante la ausencia de criterios objetivos para determinar las necesidades absolutas de gasto de las administraciones, lo prioritario es el rediseño de la distribución de recursos y el uso de herramientas tributarias que produzcan combinaciones de bienes/servicios y cargas tributarias proporcionadas. Lo cierto es que, con la llegada de recursos extraordinarios a las CC.AA a lo largo de 2020, se han producido algunos superávits.

Se analizan las causas del desequilibrio vertical en la financiación autonómica, así como las dificultades de los Estados descentralizados originados principalmente por la complejidad de una estructura plural o compuesta, aunado a la imprecisa e insuficiente articulación de sus relaciones financieras. Las competencias adquiridas de manera desigual hacen difícil establecer acuerdos sobre la financiación principalmente porque los objetivos de gasto son cambiantes y, con ello, más aún la suficiencia. Afirmar que los desequilibrios se deben a que las transferencias de nivelación vertical no responden a las necesidades de los territorios, es un enfoque simplista del problema; la solución apunta a la delimitación de las transferencias desde tres perspectivas complementarias: autonomía, suficiencia y solidaridad.

Conforme vamos avanzando en los enfoques de estudios encontramos que no solo se plantea el uso adecuado de las herramientas tributarias para la obtención de recursos, sino que se insiste en la redistribución de los ya existentes. En este sentido, se considera que la actual asignación de los recursos globales podría seguir la visión de la «tradición histórico-pactista» (p. 65); o, una redistribución acorde con los objetivos de las administraciones. Para evitar hacer uso de estos criterios históricos, se realiza un interesante ejercicio con la intención de determinar un reparto óptimo entre los distintos niveles de gobierno. Se considera el destino del gasto público consolidado agrupado por su finalidad como unidad de medida, para hacer comparaciones entre países del entorno. Esta simulación tiene como objetivo asignar los recursos financieros públicos no financieros que corresponden a cada administración con base en sus competencias. Aunque pudiera agregarse otras unidades de medida, sus conclusiones apuntan hacia una infrafinanciación del sector público autonómico.

Todo incremento en el grado de autonomía se traduce en un incremento de la responsabilidad política, económica y financiera de las CC.AA. Por lo tanto, no es de extrañar que el segundo bloque (Cap. IV-VII) comience haciendo referencia a que el ejercicio de descentralización se ve condicionado tanto por la autonomía tributaria de los gobiernos subcentrales, como por la suficiencia de recursos. Del examen de las ventajas/desventajas de la descentralización se extrae una serie de recomendaciones para la reforma del SFA de régimen común -generales y específicas: tributos y gastos, y especiales-. Es un incentivo el esfuerzo por demostrar empíricamente que la propuesta de redefinir la brecha fiscal vertical arroja datos positivos. Una cuestión importante que resulta de las propuestas para la reforma considera que, además de mejorar los procesos de rendición de cuentas de las CC.AA y reforzar la equidad horizontal de forma constante y continua; también habría que respaldar el plan de saneamiento de la deuda autonómica.

El análisis de la situación actual nos remite a la composición de la cesta tributaria, al peso de los tributos en el modelo, a reconocer que es en los impuestos directos donde se concentra la autonomía financiera. Es un llamamiento a la responsabilidad fiscal, la rendición de cuentas, y con ello, a la disminución de la ilusión fiscal. El texto señala que en el futuro se podría seguir avanzando para lograr mayor grado autonomía finan- 
ciera. Aunque la discusión no se agota, el modelo de financiación podría ser configurado para la obtención de recursos por dos grandes vías: la cesta tributaria y una mejora de los mecanismos de nivelación.

El esfuerzo fiscal es un concepto que cobra importancia en un modelo como el actual, que precisa conocer los recursos que obtienen las CC.AA y su capacidad máxima de recaudación. Hay diversos métodos para estimarlo, por lo cual se aprecia el repaso que hacen los autores a través del enfoque macroeconómico, sistema de ingresos representativo, índices relativos al esfuerzo fiscal y métodos econométricos. Esto es útil pues permite identificar dificultades en el cálculo, comparar los resultados y proponer diferentes alternativas segmentadas según la técnica de estimación empleada. Lo que es innegables es que la reforma del SFA deberá considerar, como incentivo para las Comunidades Autónomas, aquellas con mayores niveles de esfuerzo fiscal.

Este bloque cierra con los motivos fundamentales por los que se critica el funcionamiento del régimen de entregas a cuenta en el Impuesto sobre la Renta de las Personas Físicas (IRPF). El argumento gira en torno a las disparidades entre la estimación del rendimiento cedido del IRPF que realiza la Administración General del Estado y el rendimiento definitivo; así como a las diferencias temporales, desde que son tomadas las decisiones normativas por las CC.AA, hasta el momento en que, tanto las haciendas autonómicas como los ciudadanos perciben los efectos de esta medida. Es importante hacer notar la falta de transparencia en el cálculo de las entregas a cuenta, puesto que en los documentos remitidos a las Comunidades Autónomas no se proporcionar información sobre estas razones, y así no es posible reproducir estos cálculos.

El tercer bloque (Cap. VIII-XI) explora el futuro de la imposición patrimonial. En la reforma de 1977 el Impuesto al Patrimonio se introdujo como complemento del IRPF para un periodo de dos años. Prorrogado año con año, en 2008 el gobierno central acordó («eliminación de facto» p. 287) una bonificación general del $100 \%$ de la cuota integra del Impuesto. Sin embargo, para 2011 su reintroducción se justificó como una medida para que aquellos con mayores recursos contribuyeran a la recuperación económica.

Aunque se reconoce a la equidad como un fuerte argumento a favor de la imposición de la riqueza personal, hay argumentos que señalan que tanto el Impuesto sobre Sucesiones y Donaciones (ISD) y el Impuesto sobre el Patrimonio (IP) no propician la equidad horizontal y territorial, y son identificados como una vía para la evasión y elusión. Los índices de concentración de la riqueza y las herencias sugieren una disparidad de brecha superior en la riqueza que en la renta; sin embargo, aunque se puede deducir dependencia entre estos dos elementos, no necesariamente tienen correlación. En la estimación de la pobreza resulta interesante la introducción del concepto «económicamente vulnerable» y su rol dentro de la dinámica de exclusión social.

Apoyándose en la teoría del federalismo fiscal se advierten que «los tributos sobre la fiscalidad patrimonial personal no son las figuras impositivas más atractivas para su descentralización» (p. 246); por ello, atendiendo la tradicional defensa de las figuras tributarias, se realizan valoraciones tanto del IP como del ISD desde la óptica de la eficiencia y la equidad. En perspectiva internacional el IP es un impuesto en desuso que ha tomado impulso en los últimos años. Los ejercicios que comparan la tributación patrimonial en la UE ponen de manifiesto diferentes grados de descentralización fiscal y con ello diferentes tipos de exenciones, tarifas o mínimos exentos y beneficiarios de la recaudación. Las comparaciones al interior de España también confirman que las competencias fiscales autonómicas son mayores en el ISD que en el IP. Se insiste en la necesaria actualización de la normativa en materia de tributos cedidos y en el establecimiento de unos mínimos de tributación a nivel nacional, que cumplan los objetivos para los que se crearon.

Debido a la práctica de eliminación del Impuesto al Patrimonio en varios de los sistemas fiscales de la Unión Europea, no es posible realizar comparaciones con estos países. En España, la Agència Tributària de Catalunya, realizó estimaciones sobre el tax gap del IP con datos de 2014. Se apoyan en el microsimulador renta-patrimonio (SIMPA) para estimar a corto y largo plazo la capacidad redistributiva del IP. Las simulaciones han permitido verificar nuevas posibilidades de configuración del impuesto sin que esto vaya en detrimento de la recaudación o incluso de la capacidad redistributiva.

El último capítulo aborda otro aspecto interesante de analizar sobre el IP referente a las personas jurídicas y en particular del patrimonio de sociedades en general no afecto a sus actividades económicas principales. La simple idea del establecimiento de un impuesto con finalidad extrafiscal (cuya finalidad es evitar la utilización del patrimonio empresarial para fines de elusión fiscal) da cuenta de la problemática vertida. Los actos de elusión fiscal están ampliamente extendidos, deterioran el sistema fiscal en perjuicio directo de la recaudación. La regulación laxa ha permitido la proliferación de sociedades patrimoniales al admitir diferentes motivos fiscales. Estas sociedades solo han sido objeto de regulación específica para evitar la elusión fiscal en el IRPF en el periodo 2007-2014. 
Una de las claves podría estar en aquellos patrimonios afectos y no afectos al desarrollo de una actividad empresarial; la titularidad de inmuebles no afectos personifica la fiscalidad más ventajosa del Impuesto sobre Sucesiones en relación con el IRPF.

En suma, la obra es de gran utilidad conceptual, con una importante orientación empírica, ofrece diseños metodológicos, técnicas, enfoques y propuestas de mejora para el Sistema de Financiación Autonómica, que intenta reformar los evidentes desequilibrios entre la capacidad y competencias que ejercen las Comunidades Autónomas, como elemento inherente a los procesos de descentralización.

\section{REFERENCIAS BIBLIOGRÁFICAS}

Manzano Silva, M. E. (2012). Autonomía, coordinación y solidaridad en el régimen común de financiación autonómica. Instituto de Estudios Fiscales - IEF.

Calvo Ortega, R. (2015). Crisis de financiación autonómica. Aranzadi.

Lago Montero, J. M. (2014). ¿Es posible armonizar los subsistemas tributarios autonómico y local? Ars luris Salmanticensis - AIS, 2(1), 17-24. https://revistas.usal.es/index.php/ais/article/view/11965 